\title{
O LABIRINTO DAS MEMÓRIAS EM TRISTRAM SHANDY E OS PROCEDIMENTOS SURREALISTAS
}

\author{
Aline Candido Trigo - UEL/CNPq \\ Luciana Brito - UENP/UEL/CNPq
}

RESUMO: A vida e as opiniões do cavalheiro Tristram Shandy, de Laurence Sterne, é um romance de ruptura que lançara artifícicos narrativos a se firmarem como modernos, em diferentes artes. Diante disso, o presente artigo propõe uma relação entre a escrita shandiana e os ideais do surrealismo, no sentido do que demonstra André Breton acerca de serem artistas de períodos anteriores tão surrealistas quanto os fundadores do movimento. Seus ideais de totalidade do pensamento de modo a alcançar a escrita livre, a escrita automática, bem como 0 alcance de uma realidade absoluta, foram difundidas por muitos países e ultrapassaram as barreiras da temporalidade, impondo-se até a contemporaneidade. Nesse sentido, analisa-se aqui, a partir de conceitos de Walter Benjamin, a resistência dessa forma de utilizar-se da memória que caracteriza autores como Aragon e outros surrealistas, mas que teve forma inicial com o romance digressivo de Laurence Sterne.

PALAVRAS-CHAVE: Tristram Shandy. Surrealismo. Walter Benjamin.

\section{THE LABYRINTH OF MEMORIES IN TRISTRAM SHANDY AND THE SURREALIST PROCEDURES}

ABSTRACT: The life and opinions of Tristram Shandy, gentleman, by Laurence Sterne, is a rupture novel that launched narrative devices that were to be consolidated as moderns, in distinct areas. Therefore, the present work proposes a connection between shandyan writing and the ideals of surrealism, in ways shown by André Breton about artists of previous periods who were as much surrealists as the movement founders. Their ideals of the totality of thought to achieve free writing, automatic writing, as well as the reaching of an absolute reality, were spread to many countries and surpassed barriers of temporality, projecting themselves into the contemporaneity. In this way, the present paper, starting from concepts by Walter Benjamin, analyzes the resistance of this form of memory use that characterizes authors such as Aragon and others surrealists, but that had its beginning with the digressive novel by Laurence Sterne.

KEYWORDS: Tristram Shandy. Surrealism. Walter Benjamin.

é mestranda em Estudos Literários no Programa de Pós-Graduação em Letras da Universidade Estadual de Londrina.

é diretora do Centro de Letras, Comunicação e Artes da Universidade Estadual do Norte do Paraná e docente do Programa de Pós-Graduação em Letras da Universidade Estadual de Londrina. 


\title{
O LABIRINTO DAS MEMÓRIAS EM TRISTRAM SHANDY E OS PROCEDIMENTOS SURREALISTAS
}

\author{
Aline Candido Trigo \\ Luciana Brito
}

\begin{abstract}
True Shandeyism, think what you will against it, opens the heart and lungs, and like all those affections which partake of its nature, it forces the blood and other vital fluids of the body to run freely through its channels, makes the wheel of life run long and cheerfully round.
\end{abstract}

Laurence Sterne, Tristram Shandy

INTRODUÇÃO

Surgido no século XVIII em meio a transformações políticas e artísticas, bem como religiosas, o romance $A$ vida $e$ as opiniões do cavalheiro Tristram Shandy ${ }^{1}$ (1760-1767), é abordado com frequência por estudiosos na contemporaneidade, ainda que, na maioria dos casos, através da crítica comparada. Entretanto, as produções de seu criador, Laurence Sterne, ainda não receberam o aprofundamento que permitem e, como apontado por Sontag: "Sterne ainda figura como um gênio ultra-excêntrico e marginal (como Blake), que se faz notar sobretudo por ter sido bizarra e prematuramente 'moderno'". ${ }^{2}$ A partir dos estudos comparados, bem como através do ensaio de Klein, é possível observar que com Tristram Shandy desencadeou-se uma rede de intertextualidades, denominada de tradição shandiana.

Consonante a esse fenômeno das relações entre as prosas subsequentes a Sterne, o crítico Sérgio Paulo Rouanet, em Riso e Melancolia, ${ }^{3}$ constrói a tese de que as obras de Diderot, Xavier de Maistre, Almeida Garret e Machado de

\footnotetext{
${ }^{1}$ STERNE, Laurence. A vida e as opiniões do cavalheiro Tristram Shandy. Trad. José Paulo Paes. Rio de Janeiro: Nova Fronteira, 1984. Doravante referido como Tristram Shandy, o romance foi originalmente publicado entre os anos 1760-1767, e no Brasil somente foi traduzido no ano de 1984, por José Paulo Paes.

2 SONTAG, Susan. apud KLEIN, Kelvin Falcão. Performance e literatura mundial no Tristram Shandy de Laurence Sterne. Letrônica, Porto Alegre, v. 6, n. 1, jan./jun., 2013, p. 341.

${ }^{3}$ Cf. ROUANET, Sergio Paulo. Riso e melancolia. A forma shandiana em Sterne, Diderot, Xavier de Maistre, Almeida Garret e Machado de Assis. São Paulo: Companhia das Letras, 2007.
} 
Assis formam um efeito em cascata, um efeito dominó, que ocorre a partir de Tristram Shandy. Entende-se aqui que cada um dos referidos autores leram o romance de Sterne, se apropriaram de suas formas, parodiaram e/ou intertextualizaram-no. Com isso, cada autor (dos mencionados acima) que veio depois de Diderot, no caso, que é o primeiro abordado, utiliza o método de Sterne juntamente ao método que Diderot criou a partir de Sterne, e assim sucessivamente, de maneira a ampliar e dar novas formas ao romance, mas sem desvincular-se da filosofia shandiana.

Portanto, diante da relação literária que Sterne tem estabelecido ao longo dos séculos com suas produções, principalmente por meio de Tristram Shandy, pensa-se viável, para o presente trabalho, traçar uma relação com o movimento surrealista, este que utiliza alguns métodos que foram firmados a partir de Sterne. Para tanto, serão analisadas algumas ideias centrais do movimento vanguardista presentes em Manifestos do surrealismo, de André Breton, que explicitam não terem sido, exatamente, os surrealistas os criadores do movimento. ${ }^{4}$ Os almejos artísticos dessa vanguarda advêm de variadas literaturas anteriores que já indicavam possíveis caminhos de uma maior liberdade artística que, como será desenvolvido adiante, é o caso de Tristram Shandy, mesmo que de forma indireta.

Por conseguinte, com a necessidade de contextualizar o período literário de Sterne, e demonstrar de que modo o autor anglo-irlandês foi capaz de ultrapassar as barreiras literárias, da mesma maneira que o movimento surrealista ${ }^{5}$ vai clamar anos mais tarde, aqui se recorre às teorias de Walter Benjamin acerca da obra de arte e as demandas da modernidade. Para tanto, o foco residirá sobre o conceito de fragmentação e choque para Benjamin e para o surrealismo, que consiste na temática central da narrativa sterniana.

Para tanto, será levado em consideração o fator da transgressão e da subversão que se fazem presente nas produções surrealista, como será mostrado

\footnotetext{
${ }^{4}$ BRETON, André. Manifestos do surrealismo. Trad. Sergio Pachá. Rio de Janeiro: Nau editora, 2001.

${ }^{5}$ Importante ressaltar, aqui, que não são unicamente as manifestações surrealistas que se utilizam de características firmadas por Sterne. Produções artísticas da modernidade em geral, com subversões extremas da forma, podem ser relacionadas à narrativa shandiana. Como exemplo, é possível observar a colocação de José Paulo Paes que situa a linguagem shandiana como precursora da linguagem do Futurismo, também movimento de vanguarda, anterior ao Surrealismo. PAES, Sérgio Paulo. Sterne ou o horror à linha reta. In: STERNE, Laurence. $A$ vida e as opiniões do cavalheiro Tristram Shandy. Rio de Janeiro: Nova Fronteira, 1984, p. 30.
} 
adiante nos manifestos e no romance de Louis Aragon, O camponês de Paris. ${ }^{6}$ E esse ponto pode causar certo espanto, haja vista que o autor Laurence Sterne fora um pároco (da igreja anglicana). Formado em Filosofia e Humanidades pela Cambridge University, mas sem muita inclinação às crenças sobrenaturais, abandonara a carreira religiosa após curto tempo de atuação e iniciara seu polêmico romance $A$ vida $e$ as opiniões do cavalheiro Tristram Shandy.

Com publicações realizadas por volumes, ao longo dos anos 1760-67, conforme os produzia, Sterne apresenta uma narrativa em prosa satírica, irônica e obscena que, apesar de toda a agressividade aos padrões da época, teve os volumes vendidos, lidos e comentados, como mostra José Paulo Paes ${ }^{7}$ na nota introdutória. O fenômeno, inclusive, rendeu a Sterne sucesso na França, onde foi lido por Diderot, este que se tornara profundo admirador da pessoa e do artista anglo-irlandês.

Com efeito, após surgirem inúmeras obras de ficção pautadas na intertextualidade e, consequentemente, trabalhos críticos sobre estas, tornara-se evidente que as experiências literárias são repassadas de geração em geração, mesmo que de maneira indireta. Como aponta Bakhtin, não é possível haver um discurso puro, que seja desprovido do dialogismo, de experiências alheias. Um discurso sempre necessita de outro discurso:

A orientação dialógica é naturalmente um fenômeno próprio a todo o discurso. Trata-se da orientação natural de qualquer discurso vivo. Em todos os seus caminhos até o objeto, em todas as direções, o discurso se encontra com o discurso de outrem e não pode deixar de participar, com ele, de uma interação viva e tensa. ${ }^{8}$

A obra sterniana ultrapassa os limites de tempo e também os limites literários. Ao reconhecer que nada pode ser inteiramente novo, utiliza técnicas que deformam o antigo e possibilita um olhar ampliado, para além das preconcepções. Esse fator conduz à tênue linha sobre a qual reside a célebre delimitação dos Antigos e Modernos, haja vista que tais denominações receberam classificações variadas ao longo dos tempos. Dessa forma, é com-

\footnotetext{
${ }^{6}$ ARAGON, Louis. O camponês de Paris. Trad. Flávia Nascimento. Rio de Janeiro: Imago, 1996.

${ }^{7}$ Cf. PAES, Sérgio Paulo. Sterne ou o horror à linha reta, op. cit., p. 7-40.

${ }^{8}$ BAKHTIN, Mikhail. Questões de literatura e de estética. A teoria do romance. Trad. Aurora Bernardini et al. 4. ed. São Paulo: Editora UNESP, 1988, p. 88.
} 
preensível que uma produção realizada durante certo período do século XVIII ainda faça sentido e se renove no século XXI, como podemos observar a partir dos artigos que abordam Tristram Shandy em comparativo com os mais variados tipos de obras, bem como, ao observar as produções fílmicas que cada vez apresentam características narrativas subversivas em grande semelhança às de Sterne.

É diante de tais associações que se pensa viável a relação entre um romance do século XVIII e um movimento de vanguarda definido na modernidade, pois "se a originalidade deveria ser valorizada no lugar da tradição, o romance era terreno dos Modernos: o único gênero desenvolvido no século XVII que não foi uma imitação de um gênero conhecido desde a antiguidade". 9 E é justamente essa falta de demarcação específica dos períodos que incute sentido às características do movimento surrealista com uma produção romanesca como a obra de Sterne, que já fora definida como arcaica.

\section{TRISTRAM SHANDY E A SUBVERSÃO LITERÁRIA}

O romance Tristram Shandy é uma produção revolucionária, acima de tudo porque surge em um período no qual estavam em evidência romances de autobiografia. Apesar do influxo literário, Sterne não se rendera a essa forma que poderia ser o método mais seguro de sucesso. Ao invés disso, lançara uma obra que parece ter como objetivo frustrar o leitor comum, na medida em que apresenta questionamentos velados em relação à burguesia, bem como uma erudição exacerbada, seja com a menção a filósofos, seja por meio da intertextualidade com literaturas clássicas.

Além disso, como referência mordaz à moda dos romances autobiográficos, o narrador shandiano posiciona-se como autor da obra. A proposta é de que contará sua vida e discorrerá sobre suas opiniões. Mas esse processo é claramente satírico já que o narrador demonstra onisciência de fatos dos quais não poderia saber a não ser que lhe fossem contados. O narrador-personagem conta, já no primeiro capítulo da narrativa, como acontecera o momento de sua concepção.

A partir daí, Tristram encaminha a narrativa por diversas digressões e

${ }^{9}$ DORÉ, Andréa. Joan Dejean. Antigos contra modernos. As Guerras culturais e a construção de um Fin de siècle. Rio de janeiro: Civilização Brasileira, 2005. História: Questões \& Debates, Curitiba, n. 48/49, p. 433, 2008. 
conversas com o leitor, até chegar ao capítulo quatro, quando se justifica: "É por pura submissão a tal estado de espírito, e por uma relutância da minha natureza em despontar qualquer alma vivente, que tenho sido desde já tão pormenorizado." ${ }^{10}$ Nesse ponto já é possível observar a natureza provocativa e subversiva da obra.

Apesar de iniciar a narrativa no momento íntimo de seus pais que the gerou a vida, o narrador só confirma, de fato, tal evento no capítulo quatro: "Fui gerado na noite do primeiro domingo para a primeira segunda-feira do mês de março, no ano de Nosso Senhor de mil setecentos e dezoito. Estou certo de que o fui". ${ }^{11}$ Mas é no primeiro capítulo que há a descrição de como se sucedeu o fato, com seu pai sendo interrompido durante o coito pela pergunta de sua mãe a respeito dos relógios. Mais adiante, entende-se que a pergunta da mãe acontece devido ao processo de associação, ao qual Sterne referencia Locke. Quando o marido, Walter Shandy, dava corda nos relógios era o momento em que ele cuidava de todos os afazeres importantes da casa, inclusive as necessidades matrimoniais.

As técnicas utilizadas por Sterne que vão contra a concepção de uma prosa tradicional consistem em digressões, subversão do tempo narrativo, desenhos feitos pelo próprio punho do autor, pontuações incomuns como, por exemplo, travessões de tamanhos variados, parágrafos extremamente extensos que duram, por vezes, mais de uma página, dentre outros recursos. Há também páginas inteiras que exibem atitudes audaciosas como a que está toda em preto, para simbolizar a morte de uma personagem; e outra página, mais adiante, em branco para que o leitor, este que também é personagem criada pelo narrador, possa desenhar como imagina ser a personagem da viúva Wadman. Enfim, são diversas as subversões que radicalizam a cena da prosa até então atuante.

O teórico Mikhail Bakhtin, que recorre constantemente a Sterne para exemplificar seus conceitos de romance humorístico, juntamente à paródia, metaficção, plurilinguismo e demais, coloca o romancista como um autor à frente de seu tempo. Tal apontamento deve-se às críticas que existem em Tristram Shandy, pois ao realizar uma paródia do discurso de outrem, como Sterne faz inúmeras vezes, "[...] afasta ainda mais o autor de sua linguagem, complica ainda mais a relação dele com as linguagens literárias de seu tempo,

\footnotetext{
${ }^{10}$ STERNE, Laurence. A vida e as opiniões do cavalheiro Tristram Shandy, op. cit., p. 50.

${ }^{11}$ Ibidem, p. 50.
} 
sobre o próprio território do romance". ${ }^{12}$ Dessa maneira, pensa-se que, a partir de técnicas como a digressão, a intertextualidade e até mesmo com o recurso da metalinguagem, é possível observar em Tristram Shandy um indício das características que viriam a compor as propostas do movimento de arte moderna, em especial a vanguarda surrealista.

\section{FRAGMENTAÇÃO E SUBVERSÃO}

A experiência memorialística que a produção melancólica de Charles Baudelaire apresenta é pauta fundamental para a filosofia sociológica de Walter Benjamin. Ao refletir sobre a modernidade, bem como sobre o posicionamento da obra de arte na era moderna com todo o aparato tecnológico e que vai causar uma espécie de crise histérica no homem moderno, Benjamin se volta, primeiramente, às alegorias criadas pelo artista francês do século XIX. Isso se dá por conta de despontar com Baudelaire um rompimento da visão de Modernidade como contraste à Antiguidade, conforme demonstra Walter Benjamin. ${ }^{13}$ Aqui, ambos os termos "[... ] não correspondem mais a épocas distintas, e passam a designar uma relação entre o momento presente e aquele que acabou de passar". ${ }^{14}$

Em trabalhos que se voltam para as questões vanguardistas, recorrer a Baudelaire faz-se, comumente, necessário. Tal fator é apontado por Menegazzo em seu estudo sobre as poéticas de vanguarda:

A concretização da linguagem baudelaireana fundamenta-se na artificiosidade que, unida aos elementos de modernidade, resulta em uma linguagem renovada arbitrariamente, possibilitando à lírica posterior desenvolver este mecanismo de forma mais apurada e radical como, por exemplo, as imagens surrealistas. ${ }^{15}$

Diante disso, é válido destacar que Baudelaire é seguidor da filosofia shandiana, o que pode ser observado não apenas através da utilização dos recursos criados por Sterne, como também por tê-lo referenciado em um de

\footnotetext{
${ }^{12}$ BAKHTIN, Mikhail. Questões de literatura e de estética, op. cit., p. 114.

${ }^{13}$ Cf. BENJAMIN, Walter. Charles Baudelaire, um lírico no auge do capitalismo. Obras escolhidas, v. III. Trad. José M. Barbosa e Hemerson A. Baptista. São Paulo: Brasiliense, 1989.

${ }^{14}$ GATTI, Luciano. Experiência da transitoriedade: Walter Benjamin e a modernidade de Baudelaire. Kriterion, Belo Horizonte, v. 50, n. 119, , jun. 2009, p. 2.

${ }^{15}$ MENEGAZZO, Maria Adélia. Alquimia do verbo e das tintas nas poéticas de vanguarda. Campo Grande, MS: Cecitec/UFMS, 1991, p. 23.
} 
seus poemas em prosa. ${ }^{16} \mathrm{O}$ olhar fragmentado, a melancolia, a digressão, e outros, são características que perpassam ambos os autores.

Nesse sentido, Benjamin recorre ao poeta mais alegórico para refletir as formas de lidar com as transformações do mundo moderno. As demandas da modernidade não são facilmente supridas. Escapes como o ato de narrar a experiência para que haja uma troca de visão de mundo de maneira artística já não são possíveis, devido à turbulência que o labor do dia a dia exige. Assim, há grandes dificuldades em fazer com que o passado se firme e, consequentemente, que experiências sejam trocadas e, então, acrescentadas aos indivíduos. É a era da fragmentação. É o início do atrofiamento da narrativa que aponta para a revolução industrial, que tornara o homem mecanizado e vítima da demanda da pressa em prol da sobrevivência:

Se o sono é o ponto mais alto da distensão física, o tédio é o ponto mais alto da distensão psíquica. O tédio é o pássaro de sonho que choca os ovos da experiência. $\mathrm{O}$ menor sussurro nas folhagens $\mathrm{o}$ assusta. Seus ninhos - as atividades intimamente associadas ao tédio - já se extinguiram na cidade e estão em vias de extinção no campo. Com isso, desaparece o dom de ouvir, e desaparece a comunidade dos ouvintes. Contar histórias sempre foi a arte de contá-las de novo, e ela se perde quando as histórias não são mais conservadas. Ela se perde porque ninguém mais fia ou tece enquanto ouve a história. Quanto mais o ouvinte se esquece de si mesmo, mais profundamente se grava nele o que é ouvido. Quando o ritmo do trabalho se apodera dele, ele escuta as histórias de tal maneira que adquire espontaneamente o dom narrativo. [...] $\mathrm{E}$ assim essa rede se desfaz hoje por todos os lados, depois de ter sido tecida, há milênios, em torno das mais antigas formas de trabalho manual. ${ }^{17}$

Benjamin apresenta em seus trabalhos uma profunda admiração ao movimento surrealista, que paira na proposta de um novo olhar sobre algo que já

${ }^{16}$ BAUDELAIRE, Charles. Poesia e prosa. Trad. Ivan Junqueira. Rio de Janeiro: Nova Aguilar, 1995, p. 339-341. Trata-se do poema Os bons cães, no qual o poeta parodia uma passagem de Tristram Shandy e se dirige diretamente a Sterne no trecho: "Nunca me envergonhei, nem sequer ante os jovens escritores do meu século, de minha admiração por Buffon; não é, porém, a alma desse pintor da natureza pomposa que chamarei agora em meu auxílio. Não. Com muito maior gosto me dirigiria a Sterne, e lhe diria: - "Desce do Céu ou sobre dos Campos Elísios até onde estou, para inspirar-me em favor dos bons cães, dos pobres cães, um canto digno de ti, sentimental farsante incomparável! Volta escanchado nesse famoso asno que te acompanha sempre na memória da posteridade; e, sobretudo, que esse asno não se esqueça de trazer, delicadamente suspenso entre os beiços, o seu imortal maçapão! [...]".

${ }^{17}$ BENJAMIN, Walter. O narrador: considerações sobre a obra de Nikolai Leskov. In: Magia e técnica, arte e política. Obras escolhidas, v. I. Trad. Sérgio Paulo Rouanet. 7. ed. São Paulo: Brasiliense, 1994, p. 204-205. 
está à vista há tempos e sobre o qual o homem já não mais dispõe de habilidades para expressar. Com isso, é possível reconhecer no surrealismo um forte desejo em destruir ao máximo essa incapacidade narrativa, no sentido de contar detalhadamente os fatos, dando-lhes o máximo de expressividade, conforme o capítulo "O narrador", de Walter Benjamin. ${ }^{18}$

Entretanto, o movimento de vanguarda em si não surgiu como uma iluminação exata aos surrealistas. Estes, sim, buscaram interpretar outras manifestações arcaicas de nonsense, manifestações estas que se mostraram, a partir do surrealismo, ser uma condição irremediável. O próprio André Breton $^{19}$ indica autores que não integraram, de fato, a vanguarda, como Swift, Sade, Poe, Mallarmé e diversos outros, como sendo surrealistas em determinados pontos das produções. E como toda forma artística, o movimento passou por transformações ao longo das suas formas artísticas, assim como também fora modificada a maneira de vê-lo:

[...] no início, quando irrompeu sobre criadores sob a forma de uma vaga inspiradora de sonhos, ele parecia algo de integral, definitivo, absoluto. Tudo o que tocava se integrava nele. A vida só parecia digna de ser vivida quando se dissolvia a fronteira entre o sono e a vigília, permitindo a passagem em massa de figuras ondulantes, e a linguagem só parecia autêntica quando o som e a imagem, a imagem e o som, se interpenetravam, com exatidão automática, de forma tão feliz que não sobrava a mínima fresta para inserir a pequena moeda a que chamamos "sentidos". A imagem e a linguagem passam na frente. ${ }^{20}$

A revolução que o movimento pretende fazer consiste em derrubar as estruturas literárias, esquecer tudo o que foi ensinado como verdade única, e passar a enxergar todas as coisas da maneira que a mente conduzir, por si mesma. Significa alcançar um estado de pensamento que deixará o espírito livre. Dessa forma, os sonhos começam a fazer parte da concepção da realidade, e começam, então, a tomar a forma de imagens, o que significa que a vida pode ser concebida da maneira que cada um, com seu interior, é capaz de percebê-la, sem regras preconcebidas. Esse ponto é o que Benjamin abarca em Rua de mão única ${ }^{21}$ e que contribui para a explanação do cenário que dá

\footnotetext{
18 Ibidem., p.197-221.

${ }^{19}$ BRETON, André. Manifestos do surrealismo. Trad. Sergio Pachá. Rio de Janeiro: Nau editora, 2001, p. 41.

${ }^{20}$ BENJAMIN, Walter. O surrealismo: o último instantâneo da inteligência européia. In: Magia e técnica, arte e política, op. cit., p. 22.

${ }^{21}$ Cf. BENJAMIN, Walter. Rua de mão única. Obras escolhidas, v. II. Trad. Rubens R. Torres Filho
} 
vida ao movimento surrealista, ao rememorar a destruição de sua infância, de seu contexto histórico e cultural com uma técnica expressada através de imagens, de forma fragmentária.

Ademais, o ponto mais forte que o movimento de arte moderna coloca, firmado no final do século XIX por, dentre outros, Louis Aragon e André Breton, consiste em inculcar a escrita automática, de modo a alcançar a liberdade da escrita. No entanto, Benjamin enxerga no movimento algo além desses propósitos:

\begin{abstract}
Mas quem percebeu que as obras desse círculo não lidam com a literatura, e sim com outra coisa - manifestação, palavra, documento, bluff, falsificação, se se quiser, tudo menos literatura -, sabe também que são experiências que estão aqui em jogo, não teorias, e muito menos fantasmas. E essas experiências não se limitam de modo algum ao sonho, ao haxixe e ao ópio. É um grande erro supor que só podemos conhecer das "experiências surrealistas" os êxtases religiosos ou os êxtases produzidos pela droga. [...] Porém a superação autêntica e criadora da iluminação religiosa não se dá através do narcótico. Ela se dá numa iluminação profana, de inspiração materialista e antropológica, à qual podem servir de propedêutica o haxixe, o ópio e outras drogas. ${ }^{22}$
\end{abstract}

A reflexão de Benjamin acerca da importância do surrealismo para se compreender a modernidade consiste na sua teoria do choque, que parte de uma condição neurológica, com base nas teorias de Freud. O fator central dessa condição é a memória e, como explica Susan Buck-Morss, "sem a dimensão da memória, a experiência se empobrece. O problema é que, nas condições do choque moderno - os choques cotidianos do mundo moderno - responder a estímulos sem pensar tornou-se uma necessidade da sobrevivência". 23

Nesse sentido, ao adicionar a tragédia das guerras que mandavam seus homens para casa com a memória infestada de cenas e histórias terríveis, acontece a hipertrofia da narrativa. Já não há mais nada que possa valer a pena ser compartilhado por meio de uma narrativa, já não há mais tempo a ser gasto tecendo com cuidado uma história, que só poderia resultar em sofrimentos ainda maiores.

\footnotetext{
e José Carlos M. Barbosa. São Paulo: Brasiliense, 2000.

22 BENJAMIN, Walter. O surrealismo, op. cit., p. 23.

${ }^{23}$ BUCK-MORSS, Susan. Estética e anestética: o "ensaio sobre a obra de arte" de Walter Benjamin reconsiderado. Trad. Rafael Lopes Azize. Travessia, Florianópolis, n. 33, ago./dez. 1996, p. 22.
} 
É nesse ponto que Benjamin apresenta a reflexão acerca do romance, que se pauta na ideia de que tal gênero surge a partir da decadência da narrativa. Para o autor não existe nenhuma sabedoria apresentada pelo romance; o papel do romance consiste em colocar a reflexão acerca do "sentido da vida". ${ }^{24}$ Ao contrário da troca de experiências que era possível por meio do ato de tecer uma narrativa, com o romance o leitor se vê solitário:

\begin{abstract}
Mais solitário que qualquer outro leitor (pois mesmo quem lê um poema está disposto a declamá-lo em voz alta para um ouvinte ocasional). Nessa solidão, o leitor do romance se apodera ciosamente da matéria de sua leitura. Quer transformá-la em coisa sua, devorá-la, de certo modo. Sim, ele destrói, devora a substância lida, como o fogo devora lenha na lareira. ${ }^{25}$
\end{abstract}

A partir dessa concepção percebe-se que o romance sterniano não está encaixado adequadamente dentro do gênero romance. Bakhtin ${ }^{26}$ teoriza que o romance é um gênero amorfo, que constantemente se atualiza, modifica suas formas e metodologias. Com Sterne isso acontece de maneira intensa, com deboches que visam questionar o próprio gênero. Em Tristram Shandy o leitor está constantemente preso ao narrador e, para estreitar ainda mais essa relação narrador/leitor, Sterne cria a personagem do narratário, num intuito de manter viva a chama da narrativa no leitor, que pode, então, ver-se ali representado. Diante dessa atitude, Gama-Khalil, ${ }^{27}$ em seu trabalho que aprofunda a temática desse "leitor ficcionalizado" criado por Sterne, afirma:

Se o leitor se projeta na figura do narratário e interrompe a leitura, ele estará de certa forma apagando a sua existência, estará assinando, ao menos metafórica e ficcionalmente, a sua sentença de morte. Entretanto, o narrador sabe que a interrupção da leitura pode representar a morte não só do leitor, mas a sua também, o que o leva a compor estratégias de sedução ao longo da teia narrativa.

A relação que Tristram estabelece com o seu "amigo leitor", "gentil leitor" como ironicamente denominado por diversas vezes, acontece por meio de discussões e insultos. Isso porque, para o narrador, os leitores de sua história não possuem a capacidade de apreciar a complexidade da sua obra. Por

\footnotetext{
${ }^{24}$ BENJAMIN, Walter. O narrador, op. cit., p. 212.

${ }^{25}$ Ibidem, p. 213.

${ }^{26}$ Cf. BAKHTIN, Mikhail. Questões de literatura e de estética, op. cit.

${ }^{27}$ GAMA-KHALIL, Marisa Martins. Os espaços do leitor ficcionalizado: nas teias dialógicas de Henry Fielding e Laurence Sterne. Itinerários, Araraquara, n. 37, jul./dez. 2013, p. 152.
} 
acreditar que são todos tolos, Tristram utiliza um suspense extremo, sempre a prometer que contará um fato, mas já começa outro, e parte para outros temas, capítulo atrás de outro, até voltar a mencionar o que ficou retido lá atrás. Mas ainda assim não termina de contar, e começa outra digressão, pois, ao rememorar algo, a mente traz junto o momento presente, bem como outros fatores que estavam ali presentes no momento em que ocorreu o fato rememorado.

A provocação do narrador para com o leitor é tamanha, a ponto de Tristram utilizar um capítulo para falar sobre capítulos. No trecho a seguir é possível observar o seu tratamento debochado para com o leitor:

- Como pôde a senhora mostrar-se tão desatenta ao ler o último capítulo? Nele eu vos disse que minha mãe não era uma papista. - Papista! O senhor absolutamente não me disse isso. - Senhora, peço-vos licença para repetir outra vez que vos disse tal coisa tão claramente quanto as palavras, por inferência direta, o poderiam dizer. - Então, senhor, devo ter pulado a página. - Não, senhora não perdeste uma só palavra. - Então devo ter pego no sono, senhor. - Meu orgulho, senhora, não vos permite semelhante refúgio. - Então declaro que nada sei do assunto. - Essa, senhora, é exatamente a falta de que vos acuso; e, à guisa de punição por ela, insisto em que volteis imediatamente atrás, isto é, tão logo chegueis ao próximo ponto final, leiais o capítulo todo novamente. ${ }^{28}$

E a partir disso, Tristram ainda prossegue a narrativa trazendo à tona mais um leitor personagem, ao explicar a este que não pedirá desculpas quando a leitora, atacada no excerto acima, estiver de volta. Mais adiante, estende a sua crítica ao atacar, como dito anteriormente, a norma padrão do gênero romance:

Isso serve para reverberar um gosto viciado em que se comprazem milhares de outras pessoas além dela - ler sempre em linha reta, mais à cata de aventuras que da profunda erudição e saber que um livro desta natureza, quando lido como deve, infalivelmente lhes proporcionará. - A mente tem de acostumar a fazer reflexões sábias e tirar conclusões curiosas à medida que vai seguindo $[\ldots]{ }^{29}$

Não apenas o capítulo vinte, ao qual pertencem os dois excertos expostos acima, como, também, a obra ao todo apresenta certo caráter de manifesto.

\footnotetext{
${ }_{28}^{28}$ STERNE, Laurence. A vida e as opiniões do cavalheiro Tristram Shandy, op. cit., p. 94.

${ }^{29}$ Ibidem, p. 94.
} 
Ao discutir e provocar o leitor, o autor se posiciona como alguém que quer moldar uma legião de leitores específicos. O autor personagem sabe como é esse leitor a que procura; diante disso, lança desafios a este, constantemente. Como exemplo, é possível observar, ainda no mesmo capítulo, a ironia com que aborda o assunto:

Espero que o leitor masculino não haja deixado passar por alto tantas insinuações tão singulares e curiosas quanto esta em que a leitora feminina foi surpreendida. Espero que ela possa exercer os seus efeitos: - e que todas as boas pessoas, tanto masculinas como femininas, possam ter sido ensinadas, pelo exemplo dela, tanto a pensar como a ler. ${ }^{30}$

Como se não bastasse toda essa cena, que se assemelha a uma peça dramática, Sterne ${ }^{31}$ acrescenta em seguida, na íntegra, em francês, a carta que foi apresentada aos Doutores da Sorbonne com o intuito de tornar possível o batismo de uma criança ainda não nascida. Acontece aqui que a Igreja só permitia que o batizado de uma criança fosse realizado antes do nascimento quando ela estivesse em risco, mas para isso ser possível o bebê precisaria estar com alguma parte do corpo à mostra para fora do corpo da mãe.

A referida colagem da carta presente no romance, que demanda quase três páginas, não é a única, mas poderia passar simplesmente como uma técnica digressiva que é recorrente na narrativa em questão. Todavia, é possível pensar, também, que ela representa, juntamente a todo o estardalhaço no diálogo entre narrador-leitor, uma crítica às superficialidades e às crenças que causam tamanha euforia e não conduzem a nada além, e que tomam espaço de questões de fato relevantes.

Ademais, o procedimento da colagem assemelha-se ao procedimento empreendido por Aragon, ao longo de toda a prosa O camponês de Paris. Aqui, há a presença de placas de comércios, anúncios, textos em outros idiomas, dentre uma infinidade de outros procedimentos imagéticos, que faziam parte da alma do período francês abordado. O processo de colagem de tais textos e imagens acontece de forma explícita e, por vezes, irregulares em relação à disposição da escrita. Com isso, Aragon interrompe o fluxo narrativo, e cria um cenário à parte daquele descrito de acordo com a concepção do narrador.

Diante disso, é possível afirmar que em Tristram Shandy perpassa uma

\footnotetext{
30 Ibidem, p. 95-96.

${ }^{31}$ Ibidem, p. 96-98.
} 
revolta em relação à sociedade de sua época, que desprende muito tempo com frivolidades cotidianas e não se preocupa, ou se ocupa, com a busca pelo conhecimento. Destarte, não é à toa que realiza constantes referências a questões ligadas à Filosofia, Medicina, História; o passado de tio Toby, por exemplo, recebe longas páginas, em meio às digressões, para que seja apresentada sua atuação durante a Batalha de Namur, e também ao referenciar constantemente o Lillabullero, que vem a ser "uma canção que os protestantes da Irlanda, na sua luta contra os desmandos do poder real, haviam convertido 'na Marselha da Revolução Whig'."32

Seu ato de frustrar a expectativa do leitor é exposto de forma clara no texto, do início até o final, principalmente por prometer uma autobiografia do autor fictício Tristram e entregar ao leitor, em grande parte da narrativa, a história e opiniões de Toby e seu pai. O que há da vida do autor/narrador/ personagem é, em grande medida, a descrição deste sentado a escrever ou, ainda, em viagem à procura de melhores ares para a saúde. Como consequência, o que há de suas opiniões reside sobre a metalinguagem.

O que Sterne não nega a seu texto é o caráter infindavelmente humorístico, pois, apesar de toda a melancolia que o esclarecimento pode causar, o riso é capaz de atuar de maneira fisiológica e curar a bile negra. Para tanto, torna-se pertinente referenciar a seguinte passagem de Riso e Melancolia: "Tristram é um melancólico, assombrado pelo fantasma da transitoriedade, do tempo que foge, da morte. [...] Mas o narrador insere invariavelmente essas reflexões num contexto em que elas se tornam cômicas". ${ }^{33}$

Por conseguinte, deve ser observado o recurso da metalinguagem que Sterne instaura. Com esse procedimento, a história toda está entrecortada pelas explicações e justificativas a respeito de como prosseguirá com a narrativa, como se dará a construção do cenário e, também, acerca de quem participará da história. Esse procedimento que insere o leitor no processo de produção da obra, de modo a quebrar por completo a aura da ficção, é uma característica completamente inovadora, haja vista que, como aponta o próprio Tristram, o leitor comum estava deveras acostumado a narrativas em linha reta, com começo, meio e fim ordenados cronologicamente. No entanto, essa afirmação do narrador é uma clara hipertrofia do procedimento digressivo, pois realiza um capítulo digressivo que trata da digressão, enquanto este

\footnotetext{
32 PAES, Sérgio Paulo. Sterne ou o horror à linha reta, op. cit., p. 15.

${ }^{33}$ ROUANET, Sergio Paulo. Riso e melancolia, op. cit., p. 202.
} 
recurso já estava estabelecido em A tale of a Tub (1704), por Jonathan Swift.

$\mathrm{Na}$ prosa shandiana não há linearidade alguma, e sequer a proposta da narrativa é cumprida. Não recebemos dela a vida de Tristram, mas sim a vida e opiniões de Toby e de Walter Shandy. O mundo narrativo que Sterne criou é completamente caótico, um labirinto de imagens, cenas, memórias e ilustrações do pensamento. E o narrador apresenta sua história de maneira livre, da maneira que sente vontade de fazer. Houve vezes em que se mostrou obrigado pela crítica contemporânea a conter suas referências obscenas, que estavam ofendendo a "moral" e os "bons costumes". Mas quando o fez, como é o caso das passagens em que discorre sobre a importância dos tamanhos dos "narizes", faz com bom humor e muita ironia. Nesse caso em questão, Tristram começa uma defesa singela de si mesmo:

Bem, antes de aventurar-me a usar a palavra Nariz pela segunda vez,- e a fim de evitar qualquer confusão no que será referido a respeito dessa parte interessante de minha história, talvez não seja fora de propósito explicar o que pretendo dizer, e definir, com toda exatidão e precisão possíveis, o que eu desejaria que fosse entendido por esse termo $\left[\ldots . .{ }^{34}\right.$

Após uma página de digressão, na qual inclui até um diálogo com outro personagem de sua memória, Tristram finalmente elucida o que significa o nariz em sua história, mas que, pelo contexto que há na obra, tanto antes quanto depois da seguinte passagem, reside aqui uma ácida ironia:

por isso defino nariz como segue - rogando e suplicando de antemão aos meus leitores, tanto do sexo masculino como do feminino, qualquer que seja sua idade, cor da pele e condição, que pelo amor de Deus e de suas próprias almas guardem-se das tentações e insinuações do demônio e não permitam que, por qualquer arte ou artimanha, ele lhes ponha nas mentes outras ideias que não sejam as por mim postas na minha definição. - Pois pela palavra Nariz, ao longo de todo este longo capítulo de narizes, e em qualquer outra parte desta obra onde a palavra Nariz apareça, - declaro que, com a dita palavra, quero dar a entender Nariz; nada mais, nada menos. ${ }^{35}$

É possível observar que o caráter subversivo da obra de Sterne atinge, também, discussões de temas como a veracidade da história, o tempo da narrativa, assim como questões de pontuação, esta que é bastante desre-

\footnotetext{
${ }^{34}$ STERNE, Laurence. A vida e as opiniões do cavalheiro Tristram Shandy, op. cit., p. 234.

${ }^{35}$ Ibidem, p. 235.
} 
grada, como pode ser observado no seguinte trecho:

Não é uma vergonha dedicar dois capítulos inteiros ao que aconteceu durante a descida de um par de degraus? Pois não ultrapassamos ainda o primeiro patamar, há ainda quinze degraus até o pé da escada; e pelo que sei, como meu pai e o tio Toby estão com vontade de conversar, talvez haja tantos capítulos quanto degraus; - seja como for, senhor, não posso evitá-lo, assim como não posso evitar o que o destino me destina. - Um súbito impulso me atravessa - desce a cortina, Shandy - eu a desço. - Risca uma linha aqui, de um lado a outro do papel, Tristram. - Risquei-a - e vamos a um novo capítulo! Tivesse eu o diabo de qualquer outra regra para guiar-me neste assunto - e lá tenho alguma, - como faço todas as coisas sem regra nenhuma - eu a entortaria e a faria em pedaços, atirando-a depois ao fogo. - Estou por acaso arrebatado? Estou sim, já que o assunto o exige. - Bela história! Cumpre ao homem seguir regras - ou às regras segui-lo? ${ }^{36}$

Do mesmo modo, por vezes, o autor ainda substitui palavras por asteriscos ou sinais variados, sem nenhuma justificativa plausível, o que causa imediata estranheza ao leitor. Mas há momentos em que, juntamente, os asteriscos e outros tipos de símbolos desempenham a supressão da escrita de algum termo chulo ou xingamento. Juntamente aos pontos colocados até o momento, a aproximação do romance shandiano ao movimento surrealista se firma através da constante negação do próprio gênero romance que há em Tristram Shandy. Os recursos utilizados não possuem nenhuma outra função; eles querem simplesmente estar ali, sem justificativas, como ressalta Paes acerca das digressões:

Foi em razão do papel eminentemente funcional assumido pela digressão na arquitetura do Tristram Shandy que o formalista russo Victor Schklovski quis vêla exclusivamente como um 'ressaltamento do artifício artístico', uma forma 'usada por si mesma, sem motivação', quer dizer, ela não está a serviço do conteúdo ou trama do romance. ${ }^{37}$

Da mesma maneira encaminhara-se o movimento vanguardista, com a proposta de Breton: "O homem propõe e dispõe. Somente dele depende o pertencer a si próprio inteiramente, isto é, o manter em estado anárquico o bando cada vez mais temível de seus desejos". ${ }^{38}$ Juntamente a isso, equipara-

\footnotetext{
36 Ibidem, p.290-291.

37 PAES, Sérgio Paulo. Sterne ou o horror à linha reta, op. cit., p. 36.

${ }^{38}$ BRETON, André. Manifestos do surrealismo. Trad. Sergio Pachá. Rio de Janeiro: Nau editora,
} 
se $O$ Camponês de Paris, que não só apresenta pontuações desregradas ao estilo da prosa shandiana, como também apresenta similar estado de espírito, com a melancolia no olhar:

Em sua Tebaida, os leões deitados são clarões de amnésia e os fantasmas! Os fantasmas nacarados têm o ar de rezar e apagam-se. Escravo de um frisson, apaixonado por um murmúrio, não cessei de decair nesse crepúsculo da sensualidade. Um pouco mais impalpável, um pouco menos apreensível... a cada dia perco mais meus próprios contornos e enfim desejo tão pouco que me compreendam, e não compreendo mais nem o vento nem os olhares. ${ }^{39}$

Para tanto, torna-se pertinente a colocação, a seguir, do trabalho que se aprofundava na temática da transgressão do movimento surrealista:

Pode-se dizer que a transgressão da arte, no surrealismo, é a busca incessante de uma obra que é ausência de obra. Daí toda a crítica dos surrealistas ao falso poder da autoria: para conhecer a si mesmo, é preciso interrogar o seu inconsciente; para estar mais próximo da vida, é preciso estar mais distante da obra. Se o surrealismo quis manter a importância da arte para a existência humana, não quis, contudo, admitir a soberania das obras. É nesse sentido que Breton é transgressivo: no de fazer da escrita uma busca incessante da vida, e não do ato literário em si mesmo. ${ }^{40}$

Em Tristram Shandy existe certo contraponto entre o que é narrado e a forma sob a qual é desenvolvida a narrativa. A estética da obra torna-se alegoria do choque que as transformações políticas e sociais resultam. A liberdade com que Sterne cria sua obra acontece em consonância com o recurso da fantasmagoria, mesmo que o termo só tenha sido cunhado mais tarde. Seu bom humor é uma forma de mascarar a seriedade de suas críticas à sociedade, bem como à própria literatura, esta com suas regras que não são seguidas sequer em produções consideradas com formas puras. Quanto a isso, o teórico Emil Staiger ${ }^{41}$ vai apontar que mesmos estas últimas apresentam as características específicas de cada autor, o que as torna variáveis e não fixas, inevitavel-

2001, p. 33.

39 ARAGON, Louis. O camponês de Paris. Trad. Flávia Nascimento. Rio de Janeiro: Imago, 1996, p. 78.

${ }^{40}$ CUNHA, Renan P. Pereira da; PINEZI, Gabriel V. Rocha. A obra enquanto ausência de obra: a transgressão da literatura no surrealismo. Contingentia, v. 5, n. 2, nov. 2010, p. 317.

${ }^{41}$ Cf. STAIGER, Emil. Conceitos fundamentais da poética. 2. ed. Rio de Janeiro: Tempo Brasileiro, 1993. 
mente.

A maneira que Tristram apresenta seu contexto de nascimento e, também, seu contexto de produção da obra, é aparentemente inofensiva. No entanto, trata-se, na verdade, da alegoria de uma percepção caótica e fragmentária. Sua narrativa sem linearidade, sem a rigidez de começo, meio e fim, mostra o interior das memórias do ser humano, já que aqui também não há linearidade.

Em conformidade ao que foi apresentado ao longo do trabalho, o excerto a seguir vem comprovar a possibilidade da manifestação da estranheza, bem como do choque em Sterne e não apenas no surrealismo:

\begin{abstract}
Quando os formalistas russos fazem da estranheza o método artístico, o conhecimento da generalidade desta categoria permite que nos movimentos históricos de vanguarda o choque dos receptores se transforme no princípio supremo da intenção artística. A estranheza efectiva transforma-se, desta maneira, no processo artístico dominante e pode ao mesmo tempo ser tomada como categoria geral. Isto não quer dizer que os formalistas russos hajam apresentado a estranheza sobretudo na arte vanguardista (pelo contrário, o Don Quixote e o Tristram Shandy são os exemplos preferidos por Slovkij); significa apenas que há uma relação necessária entre o princípio de choque na arte de vanguarda e o estudo da validade geral da categoria de estranheza. ${ }^{42}$
\end{abstract}

A obra de Sterne concretiza-se como mais do que uma obra romanesca; ele amplia extremamente a reflexão acerca dos conceitos, subverte tão rigorosamente a ordem, que se torna possível enxergar ali um exemplo da narrativa que Benjamin diz estar morrendo. Quando Tristram começa suas divagações, contando histórias que lhe vêm à mente quando recorda outro ocorrido, isso é a memória involuntária.

\title{
CONCLUSÃO
}

Sobre o romance de Laurence Sterne paira um constante ponto de interrogação; sempre que algo é analisado dentro da obra, novos questionamentos surgem. Contudo, Tristram Shandy tem recebido estudos comparatistas que versam sobre um outro, ou outros, romances que o parodiaram. Dentre estes, no Brasil, o mais comparado pela crítica é Machado de

\footnotetext{
${ }^{42}$ BURGÜER, Peter. Teoria da vanguarda. Trad. Ernesto Sampaio. Lisboa, Portugal: Veja,
} 1993, p. 47. 
Assis, principalmente com Memórias póstumas de Brás Cubas, onde a intertextualidade acontece de maneira direta, assim como em Baudelaire.

O mais importante é que a "loucura" shandiana permanece viva nas obras que recebem dela a experiência literária. Nesse sentido, até mesmo o filósofo Friedrich Nietzsche, ${ }^{43}$ o qual insurge em Walter Benjamin em alguns pontos, deixara registrada a grande admiração ao "espírito livre" que foi Sterne, e afirmara a adoração por Tristram Shandy.

Por fim, torna-se evidente que a relação estabelecida entre o Tristram Shandy e o surrealismo ainda deixa muitas lacunas a serem preenchidas. De qualquer forma, é importante que essa sinalização comece a ser aprofundada, já que o caráter moderno de Sterne começa a ser desbravado. Além do mais, pode contribuir para a rede de relações de um movimento tão importante quanto o surrealismo, que estabelece cada vez mais sentido na efemeridade dos dias atuais, com a capacidade de criar lógica a partir de uma representação completamente nonsense. Ademais, firma-se aqui a relação que o novo estabelece com o passado, pois a memória sempre estará entrecortada por elementos do presente.

\footnotetext{
${ }^{43}$ NIETZSCHE, Friedrich. Obras Incompletas. Trad. Rubens R. Torres Filho. São Paulo: Nova Cultural, 1999, p. 112. Trata-se do volume Humano, demasiado humano, que tem por temática o "espírito livre", e traz apontamentos precisos quanto à escrita shandiana.
} 